$* * *$ Reprinted with permission. No further reproduction is authorized without written permission from Human Kinetics. This version of the document is not the version of record.

Figures and/or pictures may be missing from this format of the document.***

\title{
The Impact of Social Change on Inner-City High School Physical Education: An Analysis of a Teacher's Experiential Account
}

\author{
Ang Chen \\ Arizona State University
}

\begin{abstract}
This report analyzes changes in a traditional physical education curriculum in an inner-city high school. The analysis is based on my 14-week participant observation of classes and interviews with a veteran physical educator (Mary) who experienced community and curriculum changes during her 26-year tenure. A written chronological research narrative was examined through a framework that delineates the nature of curriculum discourses and student social capital for schooling. The findings show that the curriculum is failing because negative social changes have denied students' access to necessary social capital for successful learning. Mary emphasized a curriculum discourse of control based on a belief of dual-responsibility that dichotomizes educational opportunity into responsibility of control for teachers and responsibility of learning for students. A grounded theory developed from the case suggests that the physical education curriculum should emphasize transformation of knowledge and skills, the person, and community culture rather than reproduction of the "official knowledge" (Apple, 1993).
\end{abstract}

Curricular change is considered inevitable because various social forces, both internal and external to the school, attempt to alter the curriculum (Cuban, 1992; Locke, 1992). Social changes in society, coupled with numerous social issues facing adolescents, have long been recognized by educators as a powerful force that shapes and reshapes school curricula. Based on an extensive review of data in social changes and educational research, Berliner and Biddle (1995) argued convincingly that a real problem in education is inability of schools and curricula to address the needs of students who are in socially disadvantageous situations. These students are concentrated in inner-city schools across the nation and suffer helplessness and hopelessness (McQuillan, 1998). Similar claims are heard in physical education as well (Martinek \& Griffith, 1994). Social problems that rapidly change inner-city communities and student behavior force teachers merely to react to student resistance to the curriculum on a daily basis (Ennis, 1995; Talbert, McLaughlin, \& Rowan, 1993).

Among factors that are assumed to cause the problem, a mismatch between traditional curricula and the need to provide sufficient education to students is a

The author is with the Department of Exercise Science and Physical Education at Arizona State University, Tempe AZ 85287-0701. 
crucial one (Berliner \& Biddle, 1995). A traditional curriculum usually consists of a set of knowledge and skills prescribed by educational authorities and teachers. The knowledge and skills are considered of most worth for all to learn, generation after generation. A fundamental assumption for the traditional curriculum is that knowledge and skills in the curriculum can be taught anywhere regardless of particular social, cultural, economic, and political contexts in which schools are situated. Learning is portrayed as a process of reproducing knowledge and skills in the curriculum as they are covered by the teacher. Students are assumed to be free of influences from local sociocultural values while learning. Their prior knowledge and conceptions about the subject matter, education, and society are often viewed as misconceptions that need to be replaced with the knowledge and skills in the curriculum (Doll, 1993).

The traditional curriculum is taught in a decontextualized way. It is often conceptualized as a product manufactured in but unrelated to the context in which it is implemented, even though sociocultural issues in the context are recognized and acknowledged by curriculum designers (Cornbleth, 1990). Teaching becomes dependent on resources from the society and yet is expected to be free of societal influence. Thus, the curriculum is taught in a teacher-to-student linear process. Students are expected to master the knowledge and skills regardless of the meaning of the mastery to their lives. A traditional physical education curriculum for secondary schools shares these characteristics (Kirk, 1993). The content usually consists of multiple activities that are assumed to benefit all students. This curriculum imparts little in-depth knowledge and skills of the discipline and is taught with a multi-activity approach that emphasizes minimal relevance of the content to students' lives outside of school. For example, fitness often is taught in a way as if it is the ability to do push-ups, sit-ups, and other test-required exercises ( $\mathrm{O}^{\prime}$ Sullivan, Siedentop, \& Tannehill, 1994).

For years, the traditional curriculum has dominated secondary physical education programs. Consisting of traditional sports, mainly popular team sports, the curriculum has failed to provide meaningful knowledge and skills that address inner-city students' needs derived from their specific situational and personal contexts (Ennis, 1995). As Kirk observed (1990), although the curriculum is designed to help students achieve certain educational goals and objectives, the goals and objectives are decontextualized. A traditional curriculum ignores the fact that knowledge and skill acquisition are based on personal construction of meaning. The goals and objectives fail to recognize individual students' qualitative, subjective, and humanistic experiences associated with changes in a particular social, cultural, political, and economic context (Kirk, 1990).

Social changes are considered the most powerful contextual influence that alters school curricula during the most recent three decades (Lieberman, 1992). Negative social changes in inner-city communities, as Berliner and Biddle (1995) documented, have created a disadvantageous learning environment for students. These students face poverty, crime, unemployment, and other threats in their daily lives. They are extremely vulnerable to multiple high-risk behaviors, such as substance abuse, teen pregnancy, and dropout (Carnegie Council on Adolescent Development, 1989). The impact of these social influences, coupled with sociocultural, community demographic, and policy changes, is so powerful that it can rapidly change sociocultural values in urban communities. Students are becoming less likely to share the values, beliefs, and norms emphasized in the traditional curricu- 
lum (McQuillan, 1998). Moreover, they tend to challenge and reject them. Anyon (1997) observed that students' resistance often leads to modification and reconstruction of the curriculum by school authorities. Unfortunately, such an effort rarely generates an ideal curriculum. In contrast, a curriculum created under such pressure likely overlooks the value conflict. The new curriculum is likely to be a re-creation of the traditional, decontexualized one (Anyon, 1997; Ennis et al., 1997).

Consequently, the traditional curriculum is bound to be changed against educators' will in inner-city schools more often than in other social settings (Lieberman, 1992). In this paper, I describe such an unwanted curriculum change in Midtown High School, a school in a troubled inner-city neighborhood, as it was witnessed, experienced, and relived by Mary, a veteran physical education teacher. Through an examination of curriculum documents and extensive observation of instruction for 2 years, I determined that physical education teachers in Midtown adopted a traditional physical education curriculum. This curriculum was characterized by offering popular individual and team sports with a multi-activity approach (Ennis et al., 1997; Siedentop, Doutis, Tsangaridou, Ward, \& Rauschenbach, 1994).

This case study was inspired by and evolved from my frequent interaction with the physical education teachers in Midtown. For many years, Mary served as a cooperating teacher for a physical education teacher preparation program in which I was an instructor. During numerous conversations with Mary, I noticed that she often referred to her early years of teaching as "good years in my career." She indicated many times that her curriculum changed drastically, not for "a better education" but for students' "psychological reasons."

In this paper I also attempt to interpret the process of the curriculum change as it intersects with social changes. When analyzing a set of data from my participant observation of classes and interviews with Mary, I drew upon an analytical framework of critical pedagogy to form a grounded interpretation of the curriculum change. The term critical pedagogy is used here to describe a school of theories that analyzes interactive influences between the curriculum and society, politics, and economics (Pinar, Reynolds, Slattery, \& Taubman, 1996). The core proposition of this voluminous body of scholarship in curriculum inquiry is that the curriculum cannot be understood unless it is contextualized socially, economically, and politically (Carlson, 1992). The study of hidden curriculum (Apple, 1975; Bain, 1976, 1990), for example, is one of the best known efforts in this scholarship. Physical education scholars from this theoretical perspective tend to examine influences of culture, socio-economic status, social changes, gender, race, ability, religion, sexual orientation, institutional power, and many other factors on human movement and the physical eduation curriculum (Fernández-Balboa, 1997). Within this broad framework, I situate my analysis, particularly in the theoretical work regarding ideological conflict in the curriculum (Apple, 1993) and students' social capital for school success (Stanton-Salazar, 1997).

\section{The Ideological Conflict of Curriculum}

Ideology is defined as a set of meanings and ideas reflecting values and beliefs of an individual, a group of people, or a culture. It is a framework for individuals to give meaning to their lives (Stanley, 1992). Apple (1990) argued that ideology in education reflects values and beliefs generated from practices that are lived by teachers and students as well as those residing at an abstract level. A 
curriculum teaches not only knowledge but also sociocultural values that are indorsed and enforced by the school authority. In most cases, these values represent those of dominant sociocultural forces. From this perspective, knowledge and skills that get taught in a school are never value-free.

Once knowledge and skills are institutionalized in the form of a curriculum and taught as subject matter content in school, they become official knowledge (Apple, 1993). For students to successfully learn the official knowledge, Apple (1993) concluded that the curriculum should be "integrally linked to the political, cultural, and economic experiences of people in their daily lives" (p. 41). A difficulty for creating a curriculum for socially disadvantaged students to learn successfully lies in an ideological conflict between the values of the dominant social groups and those of socially disadvantaged in inner-city communities (Ennis, 1995; McQuillan, 1998). For the dominant social groups, according to Apple (1993), the curriculum is seen as a means to defend their property rights, a power to establish and maintain an access to educational resources and social relationships based on ownership of material and ideological properties. Apple (1993) also pointed out that for socially disadvantaged groups, a worthwhile educational opportunity is embedded in a curriculum that enhances person rights, a power needed for a person to establish and maintain the access to the same resources and relationships based on the simple membership of a human being in the society. Thus, the values and relevance of a traditional curriculum, taken for granted by dominant social groups, are constantly being questioned by socially disadvantaged groups (Apple, 1993). In this ideological conflict, successful learning of students in inner-city schools relies on how well they can cope with a curriculum that transmits knowledge and skills based on sociocultural values inconsistent with their own.

The school, as a social institution, is charged with two general responsibilities by the society: protecting and educating children (McQuillan, 1998). Accordingly, the curriculum represents two institutionally sanctioned discourses: exercising control to protect and disseminating subject matter knowledge and skills to educate (Stanton-Salazar, 1997). I use the term curriculum discourse to describe what is being said about the curriculum in both overt and covert languages and the way that ideas in the curriculum get communicated among and between teachers and students (Jewett, Bain, \& Ennis, 1995; Pinar et al., 1996). Successful learning can only be accomplished when students understand both curriculum discourses and appreciate the separation of the curricular functions of controlling and educating. In due course, as Stanton-Salazar (1997) observed, students are expected not only to have the ability to attend to the subject matter in order to be educated, but also to have the ability to interpret and comply with the control function in order to be successful in learning. To do so, a student must be willing, above and beyond any learning activity, to obtain and secure necessary social capital, which is defined as an individual student's position in a network of social relationships with the curriculum, teachers, peers, and family members in the context where he or she receives formal schooling (Stanton-Salazar, 1997).

\section{Social Capital for Successful Learning}

Learning is a socially interactive activity. A student's success in coping with the ideological conflict depends on his or her social capital, especially the interactive relationship with teachers who control the resources and opportunities for 
successful learning on a daily basis (Stanton-Salazar, 1997). This student-teacher social relationship furnishes the teacher with a rationale for deciding what, how much, and to whom to teach (Page, 1987). Thus, opportunities to learn for students is socially distributed (McQuillan, 1998). To gain access to this opportunity, students use the social capital as a necessary asset to secure their achievements and mobility in both school and society (Stanton-Salazar, 1997).

To obtain and secure positive social capital for learning is extremely difficult for socially disadvantaged students, including those from most inner-city communities (McQuillan, 1998). The ideological conflict between the curriculum value (maintaining property rights) and personal sociocultural value (emphasizing person rights) (Apple, 1993) escalates to a battle between teachers enforcing and students resisting the curriculum on a daily basis (McQuillan, 1998). In this battle, teachers are unlikely to train students how to take an advantageous position with regard to teacher-student and curriculum-student relationships, especially with regard to the control function of the curriculum. Providing such training would eventually undermine the meritocracy foundation of education that claims mastery of knowledge and skills to be the sole indicator of success in learning (McQuillan, 1998; Stanton-Salazar, 1997).

The knowledge and control curriculum discourses are not likely to be disseminated equally in physical education. Whether the curriculum emphasizes subject matter knowledge or control of students is negotiated between the teacher and students overtly or covertly (Ennis, 1995; O'Sullivan et al., 1994). The outcome of the negotiation is determined by the extent to which dominant social values in the curriculum are compatible with the values of students and their communities (Page, 1987). It is believed by the dominant social forces that knowledge and skills in the traditional curriculum are ideological properties that should be inherited by all (Apple, 1993). Wherever this belief is not questioned by students, the curriculum discourse of knowledge and skill prevails. When a group of students is denied the access to the property in their lives, two consequences will occur. One, the students are unlikely to consider the ideological property to be theirs. Two, they question the way they are taught to gain access to the property (Apple, 1993; Page, 1987).

In an ethnographic study of two schools, Page (1987) found that in both high-track and low-track classes, the values in a traditional curriculum, which centered on intellectual knowledge and basic skills, were easily accepted by the students from "upper middle-class, professional families" (p. 89). These values, however, were rejected by "typical blue-collar kids" (p. 89) in another school, who were from middle-income, but working-class, skilled worker families. While the teachers in the first school could concentrate on the curriculum discourse of knowledge, the teachers in the second school emphasized that of control in creating and maintaining a "tightly disciplined" order in their daily teaching (Page, 1987, p. 90). Recent studies on inner-city physical education (Ennis, 1995; Ennis et al., 1997) have demonstrated a similar pattern of this curriculum differentiation. Physical educators in inner-city high schools tend to emphasize control of students at the expense of their learning.

The rationale for choosing this framework to examine Mary's account of curriculum change lies in the fact that a traditional physical education curriculum is indeed a representation of the official knowledge of human movement sanctioned by dominant social and cultural forces (Fernández-Balboa, 1997). The cri- 
sis in inner-city school physical education and curriculum changes may not be understood fully if our analyses of these incidents experienced by students and teachers (e.g., Carlson, 1995; Ennis, 1995; Ennis et al., 1997; Martinek, 1996) are taken out of their social, cultural, and political contexts. My interpretation of Mary's experiences focuses on the conflict between the context and curriculum, students' role as curriculum changing agents, and a grounded theorization of the curricular change. By no means, however, does my interpretation suggest any form of generalization beyond Mary's account and Midtown High School. All names used in the report are pseudonymous.

I present the study as a chronological research narrative, a form of interpretive research, based primarily on Mary's recollection of events that caused the changes of the curriculum during a 26 -year period. The research narrative approach was chosen because it permits me to present a "natural historical inquiry" (Erickson, 1986, p. 146) to unfold the process of the curriculum change in Midtown High School. It also enables me to capture and reconstruct the phenomenon of the curriculum change for readers to share, probe, and interpret based on their own experiences as teachers, administrators, or curriculum researchers.

\section{Methods}

\section{The Context}

Midtown High School is one of the largest high schools in the urban district of a major metropolitan area in the pacific United States. The city is known for its multicultural atmosphere. The population consists of peoples associated with many cultural traditions. Residents live along socioeconomic lines. Most working-class, low income, or lower-middle income families settle in neighborhoods around urban industrial areas, while affluent families live in suburbs or in upscale residential buildings in the business district of the city.

Midtown High school serves students from a working class community with lower-middle and low incomes. Most parents of the students hold two long-hour non-professional jobs to support their families. The majority of the residents in the area live in apartment and condominium buildings. A few blocks from the school is a large federal housing complex that provides shelter for qualified low-income families. Although most residents in the complex are recent immigrants from Southeast Asia and South America, some are from local communities. Not far from the school is a community recreation center. Its gymnasium houses two basketballvolleyball courts. Outdoor facilities include a baseball park, four tennis courts, and a swimming pool $(25 \times 25$ yards $)$. Although at times I saw children going into the gymnasium, I rarely found them using the outdoor facilities. A "Closed" sign was displayed at the pool despite the mild tropical weather in the region that permits swimming to be a year-round activity.

Student enrollment was 2,311 (56\% male, $44 \%$ female) at the time of the study. The student population represented seven major ethnic groups in the region, all of whom are people of color. Yet none of the ethnic groups or its culture is in a dominant position. European Americans are not a major ethnic group and were under-represented in the school. The free and reduced lunch program involved $27 \%$ of the students. According to the principal's conservative estimate, more than $60 \%$ of the students in Midtown High School were working after school to help 
their families or to support themselves. Midtown has a child care center that provides free daytime child care for students who have children. Local gangs have a tremendous influence on students' lives both on and off campus. Mary and other teachers indicated that more students were associated with gangs or involved in gang-related activities than those participating in after-school sport programs. Although the school once won the district's outstanding school award in early 1980s, it has become known in recent years for on-campus gang violence. For example, a tragic gang fight involving knives and guns occurred in the first week of the semester when the study was conducted. The fight left one student critically injured, nine arrested, and three prosecuted for attempted murder.

Control of on-campus violence is the most important concern of the school administrators and teachers. Campus security is tight. About a dozen security guards patrol the campus regularly. At times, police officers join in the patrol. The school buildings, including offices, classrooms, gymnasium, and locker rooms, are protected by iron-barred gates and windows. The campus is heavily fenced, and only one entrance remained open during school hours. Physical education facilities include a gymnasium, a football field, a track, a swimming pool, a weight room, six tennis courts, and a regular classroom equipped for gymnastics. Most facilities appeared to lack routine maintenance. They were in useable but poor condition. The 400 -meter track lanes were covered with 6-inch tall grass. A trail in the middle of the grass seemed to be the only lane that students could run in without stepping on the grass. Most weight machines were rusted, and all were products of the early 1970s. Large cracks in the swimming pool forced the teachers to cancel all swimming classes 2 years ago. The water has been drained since. According to Mary, repair does not seem to be on the administration's agenda because opening the pool means hiring more security guards to control behavior problems that might cause fatal accidents.

\section{The Teacher}

Ms. Mary Brown was the key informant for this study. She has taught in Midtown since 1969 and is the only teacher in the physical education department who witnessed social changes in the community and experienced the curriculum change over the 26 years. Mary is the chair of the Physical Education Department, staffed with two female teachers including Mary and three male teachers. The other female teacher was newly certified and recently hired in the current school year. One male teacher had taught in Midtown for about 10 years, the other about 7 years. The third male teacher moved into the area a year ago with about 10 years of teaching experience in an east coast state. He started teaching at Midtown full time when the study began. According to Mary, there used to be about 8 to 10 physical education teachers at Midtown. Several teaching positions were eliminated or transferred to other schools because of low student enrollment in physical education since the mid-1980s.

Mary is a European American of about 55 years of age and about $5 \mathrm{ft} 4 \mathrm{in}$. tall with well toned muscles. She is from one of the Great Lakes states and moved to this area 28 years ago. Mary once lived in the community with her husband and a 5-year-old daughter adopted from an Asian country, but she moved out a few years ago to avoid trouble. I assume Mary is from an upper-middle class family. (Her parents had "a big house with a swimming pool.") When attending suburban private elementary and secondary schools, Mary was trained in gymnastics and diving after school. She considers herself very well trained and an expert in these 
activities. As a former gymnast, she always wears a gymnastic leotard under a Tshirt, shorts, and a pair of Nikes in the school. When teaching, Mary speaks with a loud and clear, authoritative voice that can be easily understood. She starts her class promptly even though she has to repeat the instructions to those students who come late. Mary emphasizes effective teaching. She comes early to prepare equipment, check facilities, and plan task organizations. Mary knows that her students are not motivated, but she refuses to adopt a roll-out-the-ball approach to teaching and makes sure that it is not practiced by her colleagues as well. She has an excellent rapport with students. They like her even though they do not like the content she teaches. Many times students indicated that they participate in the class because they do not want to make Ms. B feel bad.

Mary attended a university in the Midwest and earned bachelor's degrees in both physical education and science education. After graduation, she taught as a substitute physical education and science teacher for 2 years. Although she was offered a full-time science teacher position, Mary became frustrated at not being able to land a full-time position in physical education, which was (and still is) the only content she felt passionate to teach. After these 2 years, Mary decided to go back to school for a master's degree in physical education. She received her master's degree from a highly respected physical education teacher preparation program in the Midwest. Her parents rewarded her with a short vacation to this Pacific state. Mary fell in love with the tropical weather and the multicultural atmosphere and moved to the area shortly after her vacation. For 2 years before she started teaching full-time at Midtown in 1969, Mary coached part time in gymnastics, swimming, and diving and waited tables in local restaurants.

Mary has been very proud of being a physical educator and has enjoyed teaching physical education. Comments from her colleagues and school administrators showed that she is well respected as an excellent teacher. She is on the school curriculum committee. Her suggestions about teaching are well received by her fellow teachers across the campus. Her knowledge and expertise about organizing students in open space are well known in the school. Teachers on campus frequently come to her for suggestions for organizing students for field trips and outdoor activities, especially for activities on beaches or other water front environments. She has been nominated as Teacher of the Year many times and awarded the honor twice by the local Association for Health, Physical Education, Recreation, and Dance. Mary has been involved in developing the physical education curriculum guides for the district and state over the years and is responsible for revising the school's physical education curriculum. She is often called upon by the state curriculum supervisor, who oversees physical education across the state, to offer orientation and in-service workshops to new and experienced teachers.

\section{The Physical Education Curriculum}

According to Mary the primary goals of physical education in Midtown are:

To give students a well-rounded understanding of the history and rules of sports, primarily in team sports, [such as] softball, basketball, soccer, volleyball, flag football, and to give them training to master standard performance in playing the sports ... so everybody will take interest in these particular [sport] areas. 
These goals are documented in the curriculum guide and reflected in objectives in unit plans. It is evident that the curriculum goals are based on the decontextualized assumption that the knowledge and skills of popular sports are neutral, value-free content for "everybody" to learn and master (Cornbleth, 1990). In other words, it is expected that knowledge, skill, and interest in playing the sports should be reproduced in each student.

In Midtown High School, students are required to take one-half credit of physical education in the 9th grade and another half in the 10th to fulfill their graduation requirement. Elective courses (gymnastics, weight training, and general sports) are available for students to take concurrently with or after completion of the required courses. Those who fail to pass the required courses have to repeat them until the one-credit requirement is fulfilled. Each sport is organized into beginning, intermediate, and advanced courses to match students' skill levels. All classes are taught in a coeducational environment. Fitness development is an important content in the written curriculum documents. However, it is taught only as part of warm-up activities in sport units rather than as an independent unit. Student fitness levels are tested, usually one month before their scores are due in the district office.

Although the written curriculum documents indicate that students' grades should be based on their mastery of knowledge and skills, grading actually is based solely on attendance, dress-out, and participation. This attendance-based grading system is used to create and maintain an "encouraging" rather than "demanding" learning environment. A student has freedom to choose whether or not to participate after having earned enough points for an expected grade by simply "showing up" in class. Discipline is stressed, but only to the extent that students must remain with the class even if they choose not to take part in learning activities.

\section{Data Collection}

Participant Observation. I used the participant observation method (Goetz \& LeCompte, 1984) to experience Mary's classes for 14 weeks. The purpose of my observations was to gain first-hand experiences of how a traditional curriculum is implemented in this particular context. My role in Mary's classes was as a teaching assistant. She announced my role to her students when the observation began. I participated in all in-class instructional aspects as planned by Mary, but I did not take part in her semester, unit, and lesson planning, nor did I make any effort to alter her lesson plans. The observation was divided into an entry period ( 3 weeks), an intensive data collection period ( 7 weeks), and a retrieval period (4 weeks). In the entry period, I spent 2 days each week observing three classes each day to get acquainted with students and instructional routines. In the intensive data collection period, I attended all Mary's classes ( 5 days a week, at least four periods a day) to conduct in-depth participant observations. In the retrieval period, a schedule similar to that of the entry period was adopted. Observation notes were written daily after the observation hours and focused on description of the content, instructional strategies, and students' responses to the content. In each observation period, I had several classes videotaped to provide references and confirmation for the field notes. Events unobserved previously were noted during the retrieval period and added to the observation data pool.

Formal Interviews. I formally interviewed Mary three times for about 6 hours in total. The purposes of the interviews were to have Mary relive her profes- 
sional career at Midtown and reconstruct those historical events significant to the change of the curriculum. Interview questions focused on community social changes, curricular changes, and perceived conflict between the curriculum and the social context. Given the scope of this research, interview questions were organized and structured around these issues. The interviews were conducted using a semi-structured format (Patton, 1990). I audio-taped and transcribed the interviews.

\section{Data Analysis}

I began analyzing observation notes and interview transcripts as soon as they were collected and transcribed. A constant comparison approach with an open, axial, and selective coding system was used in the analyses (Strauss, 1987). In open coding, observation notes and interview transcripts were fractured sentence by sentence to generate independent categories and subcategories. In axial coding, the fractured data that shared a common property were combined to form a central axis that reflected meaningfulness of the category. This process produced a high level of abstraction of the data that allowed me to move "toward the discovery of a core category or categories" (Strauss, 1987, p. 55). In selective coding, my focus was placed on the relationships among the central themes derived in the axial coding process. All data categories were sorted into an event chronology for the writing of a research narrative. A grounded theory (Strauss, 1987) was developed to describe the physical education curriculum and its change. This written case was presented to Mary for verification of descriptive accuracy.

Effects of the critical events reported by Mary on the curriculum are still observable at the present time in the school and community. Some of the events were also reported by local news media. I did find these reports and used them in the data analysis for the purpose of establishing trustworthiness of the observation and interview data. I did not, however, cite the reports in the research narrative to maintain the confidentiality of the school and the community. During the study, I attempted but failed to locate Mary's former students due to changes of their residence. Consequently their perspectives about the physical education curriculum in the 1970 s and early 1980 s are not represented in this paper. Readers should be aware of these procedural limitations and are advised to determine the limits of the study accordingly. Curriculum change is an extremely complex process and may be caused by a combination of social, economic, institutional, and teacher-development influences (Cuban, 1992; Kirk, 1990). My intention is to provide an indepth description and analysis of one factor, negative social changes, in one of many inner-city communities. Thus, readers are advised not to consider the impact of social changes reported here as the sole cause for the curriculum change.

\section{9-1983: "Sports Were All We Did."}

The traditional curriculum, characterized by the teaching of multiple sports, used to be functioning well in Midtown High before 1983. It centered on the teachers' belief that sports are value-free and that all students should learn and enjoy playing them.

I used to think that sports were sports, [sport] techniques were techniques, and that you [students] came to school, I was supposed to teach you those 
techniques. ... The major curriculum goal was to give kids a well-rounded understanding of sports and exercises and a good handle on the sport skills. A lot of time was spent on individual techniques and skills. I mean the breakdowns, more so back then than ever is now. And it was because student attention span seemed to be there. The kids really wanted to get proficient at skills, they really cared to take the time to get better. They weren't involved in "let's just play the game," even [when] they did know the rules and the skills. They were very clear that our goal was technique and skill development.

Consistent with the goals, the instruction was focused on the development of physical skills, structured practices, and written and skill tests for learning evaluation. Mary recalled that both teachers and students considered it worthwhile for students to master those sport skills and that the curriculum was relevant in helping fulfill the goals of physical education. Students enjoyed the program. They were motivated to learn, because they wanted to enjoy playing games after school and in intramural tournaments. According to Mary, the intramural programs were designed as an integrated part of the curriculum in which students could apply knowledge and skill learned and discover what skills they needed to improve.

Mary: Our classes were all coordinated with the intramural program. So at the end of each unit, we would all come together to run an intramural tournament. We used to have the tournament games in the lunch hour and after school. The classes challenged each other. . . They were much more involved with inter-class tournament play.

Ang: How many such tournaments did you organize in a semester?

Mary: I think at least two or three times back then.

Ang: Were the tournaments part of your curriculum or just for recreation or organized recess?

Mary: It was a major part of our curriculum. We physical education teachers planned the tournaments, coordinated them with the units we were teaching. We thought that tournaments could provide them a real game situation where they could use the skills, strategies. If they found something they needed to work on further, they came back to our class to learn and practice.

Students were tested on physical skills and cognitive understanding of performance mechanisms, rules, and other knowledge associated with the sport. For example, one of the questions in a written examination that I found in the documents of a football unit was how spin helped a football travel. Performances on the tests formed the basis of grading.

It is apparent that throughout those years Mary, and presumably other teachers as well, repeatedly taught the traditional curriculum to different generations of students. Knowledge and skills in those sports were reproduced generation after generation. The curriculum goals were achieved when the students could demonstrate their ability in playing the sports. Although the curriculum seemed to be functioning well, it was apparently decontextualized. Conceptually, the content was considered value-free. As Mary put it, "Sports were sports; [sport] techniques were techniques." The knowledge and skills in the curriculum were thought to be acceptable for everybody. Operationally, the content was organized, taught, and 
evaluated in a linear way in breakdowns of sport skills. When asked how the program helped students in their daily lives, Mary recalled that students could play games in the recreation center after school and on weekends but seemed unaware whether or not the students played in the way they were taught.

Despite being unaware of the effect of curriculum on students' everyday lives outside of school, Mary did consider the period of 1969-1983 the best time in her teaching career. In addition to the excellent training she received in her teacher education program, Mary attributed the effective implementation of the curriculum to the stable and peaceful life in the community and students' compliant behavior. She observed, "Students were more caring, extremely respectful, not only of teachers, facilities, but of each other, and of themselves."

Anyon (1997) and MaQuillan (1998), in their ethnographic investigations of crisis in urban schools, found that the urban schools they studied had a successful past, when the dominant social and cultural values reflected in the school curriculum were accepted by both teachers and students (and their families). Consistent with these findings, the success of Midtown physical education during this time indicates that sports and other activities in the curriculum were viewed as neutral and value-free and were cherished by both students and teachers. Further, the success in the past suggests that the ideological conflict between property rights and person rights (Apple, 1993) was not a threat to the physical education. The view that sports are a type of ideological property for all was well received by teachers, students, and people in the community. According to Mary, the opportunities to access the property seemed to be available for the majority of students through playing the sports in intramural tournaments and the community recreation center.

Mary's account for this period represents a belief that successful teaching relies on a context where there is an "easy-to-teach" student body (Page, 1987, p. 84). In this context, the two curriculum discourses, control and knowledge, did not compete for Mary's energy and effort in teaching physical education. The curriculum discourse of knowledge dominated the teaching-learning process and was never challenged because, as Mary indicated, students were "more caring, extremely respectful, not only of teachers, facilities, but of each other, and of themselves." The control discourse of the curriculum was little needed as the students' behavior was compliant with teachers' expectations and consistent with the school and social culture that defined the official knowledge in the curriculum (Apple, 1993). The effective implementation of this traditional physical education curriculum in Midtown during this time might have resulted from such a school and social context where the dominant social values were shared by both teachers and students. This sharing created a school culture for Mary to emphasize the curriculum discourse of knowledge, with minimal needs to exercise the discourse of control.

\section{3-Present: "What's Wrong With Our Kids?!"}

As Mary recalled, student behavior used to be compliant in the early years of her teaching. She thought that their compliant behaviors in the classroom resulted from living in two-parent families and in a safe community, which she did not notice and appreciate until recently. The peace started to decay in the late-1970s and early-1980s.

Changes in inner-city communities and schools across the U.S. have been profound since the 1970 s and have had a negative impact on education (Berliner \& 
Biddle, 1995; Flaxman \& Passow, 1995, Lieberman, 1992). Mary reported drastic, negative social changes in the immediate context around Midtown High during this period, characterized by substance abuse, family disintegration, and gangs. Local news media once reported that the FBI's largest seizure of cocaine in the state occurred in this neighborhood. Mary thought that the situation was hopeless because drugs became available for students.

Drugs came in and became more prevalent in the community. It's never been like this before. I mean that there has always been drugs out there for many years. Prior to the $70 \mathrm{~s}$, there were drugs. Before that, looking at the 60 s and $50 \mathrm{~s}$, yeah, there were drugs. Prohibition, I mean alcohol was a drug; cigarettes, too.... But this time ... things became available at the kids' level and it was really mind-altering, and it was attitude-altering, and it was societyaltering.

Alcohol is another problem: "Strongly over here is alcohol. Teen alcohol is very heavy here in the community, really strong. It seems everybody drinks, boys and girls. This changed the community, and then the school." When touring the community recreation center, I frequently observed scores of empty beer cans and wine bottles littered around the outdoor facilities. Although it may not be inferred that they were left by Midtown High students, they do serve as a strong sign of excessive alcohol consumption in the community. They are also an indication that the state law prohibiting alcohol drinking in public facilities is violated in this recreation center.

Family disintegration and dysfunction are other major factors that Mary believed had a critical impact on students' behavioral change. Consistent with the figure I obtained from the school administration, Mary estimated more than $30 \%$ of the students in Midtown High were living in dysfunctional families or foster family situations.

A lot of the students come from dysfunctional families, so dysfunctional that for some of them, their families do not exist. I mean the main members of their family, mother and father, are not present in their life. It's aunt, uncle, brothers, or sisters, or even a friend, or not even a friend, a foster somebody. I would say that about $35 \%$ of my class is coming from that situation.

Sometimes, the two-parent family does not function as it is expected because both parents are working long hours.

For the rest of students, maybe they have two parents, but both parents are working very, very hard and are gone for the crucial part of the day, leaving the house at about five o'clock. The kid wakes himself [herself] up, gets himself [herself] ready, and motivates himself [herself] to come to school if he [she] wants to. When the kid gets home, the parents still aren't at home. They are returning home about 5:00 or 5:30 in the afternoon. Or not at all, as they are doing double shifts. A lot of parents are doing two jobs.... They are still not in the family structure.

Gangs are a serious problem in the community and the school. Mary speculated that because the dysfunctional family structure cannot meet students' needs for social affiliation and bonding, gangs have become the site where teenagers may find "friendship and trust." She observed that the nature of gangs has changed 
from gatherings of students who share similar interests to groups of youngsters who attempt to devastate the community.

It's not like a group of kids wearing the same shirts and hats or singing the same songs any more. It's a survival kind of situation - they use any means available to rob and steal, to take whatever they want to. They protect each other and fence themselves out.

Information gathered in and outside the school indicates that gangs are active on and off campus. Reports from the school administration showed that most fights on campus were gang related. Local news media once launched an extensive serial report revealing the gang problem and its social consequences in Midtown and the community. After the shooting incident mentioned earlier, the principal was transferred because of his inability to solve gang problems on campus. The new principal appointed by the board of education is the former director of the state juvenile correction center who has extensive experiences working with "troubled kids." An editorial in the local newspaper regarded her appointment as the state's most decisive effort to bring Midtown High School around and to fight street gangs in the neighborhood.

Mary thought that these three factors-substance abuse, family dysfunction, and gang involvement-were the most vicious changes in the community and had a destructive influence on student behavior, the school's mission, and her physical education curriculum. The entire student population became the victim of these social changes.

It's amazing to see how a few bad kids can change the behaviors [of others] in the school. I can still remember when there wasn't even a swear word ever on this campus when I started teaching here. You never heard the $f$-word, ever. Now, you hear it like it's an if and $o r$. It became a connecting statement. They say it when they missed a shot; they say it when they made a bad pass. It's horrible. That changed the school, changed the entire program here in Midtown.

These student behavior changes forced the school administration to adopt and enforce new security policies. Although the policies were for the safety of both students and teachers, they also altered curriculum.

Because of the escalation of vandalism and fights on campus, security guards joined the school staff.... We had to have security guards. We had to have security guards! We never had them before! That changed everything. Nothing in PE was the same as it used to be.

With the increase of administrative concerns for safety, lunch time and after school intramural programs had to be supervised by security guards as well as teachers. The intramural program was eventually terminated for the same concern after two gangs used a game to "square off" for their street status. Mary said with frustration,

We had to stop our lunch time program because of fights and the consequent liability. The state got sued because a gang fight broke out in the gym, and there were not enough teachers to deal with it. It ended up with the state having to pay big bucks. That stopped the whole [intramural] program. 
The community recreation center is no longer a safe place for after-school sports and activities. At least it is unsafe to use the outdoor facilities. According to Mary, children's active lifestyles are substituted with sedentary entertainment because parents want to avoid unexpected incidents.

To keep their kids out of trouble, the parents have to encourage a plug-in policy, having kids watch TV, buying video to keep them entertained, giving them a little plastic play house in the yard that is supposed to be the activity area, etc. Those have substituted for playing sports and exercising in the community.

This lifestyle prevents Mary from implementing the curriculum effectively. When students reach high school age, few are adequately prepared in either skill and fitness to learn the content in her curriculum.

They are in much worse shape than were those I had years before. So in order to even go into the physical fitness [testing] program, I have to teach the technique of sit-up at this age of 9 th, 10 th, 11 th, 12 th grade. At the meantime you also have to realize that some of these kids can even hardly get out of a chair, let alone do sit-ups. ... In sport areas, we have to teach the very elementary skills all over, like chest pass in basketball.

My observations echo Mary's comments. Avoidance of rigorous activities was noticeable in many students. For instance, only 11 students in a class of 25 participated in a flag football unit, while 21 in the same class participated in a billiards unit, which Mary called an "entertaining unit for psychological reasons." The most serious damage to the curriculum was caused by students' devaluing physical education and exercise.

They think playing sports or exercising should be entertainment, like watching TV or playing Nintendo. For anything that is not entertaining, they refuse to do it. This attitude toward physical education absolutely changed our curriculum, no doubt about that.

Mary's remarks suggest that she viewed her students as both creators of a disruptive learning environment and victims of their own creation. When students chose to overtly demonstrate their resistance to the curriculum, Mary attributed the behavior to their unwillingness to take full responsibility for their own education, "for anything that is not entertaining, they refuse to do it." Apparently, Mary, like many teachers in similar inner-city crises (Carlson, 1992; Page, 1987) upholds a well-received, typically professional middle-class (as opposed to the blue-collar middle-class) American belief about education. That is, as MaQuillan summarized (1998), educational opportunity presents itself to anyone when they enter into a school, especially a public school where education is free for all. Whether or not to take this opportunity, however, is the responsibility of the student.

This view is limited. Students' willingness to take the responsibility for their education is not a personal choice only; it is a socioculturally constructed choice based on their social capital for schooling (McQuillan, 1998). A traditional physical education curriculum often emphasizes the values of the dominant culture (Ennis, 1995; Fernández-Balboa, 1993) and implicitly requires students to have a base of social capital associated with the culture, such as that found in those who live in two- 
parent, professional, middle-class families with ample time and opportunity for extracurricular activities and who live in drug- and violence-free communities. With most students being people of color from blue-collar families, living in drug- and violenceplagued neighborhoods, and having to work after school, the social capital for successful learning in this traditional physical education curriculum is minimal for the students in Midtown High School. This curriculum is less likely to be perceived by the students as meaningful to their lives. Thus, there is little student concern for seeking and obtaining the necessary social capital for successful learning in physical education. In Mary's classes, the only social capital that a student can possibly have or is willing to obtain is a good teacher-student relationship with Mary.

Students' social capital for schooling is assumed to enable the students to understand what is expected of them in terms of the two curriculum discourses: control and knowledge. Teachers expect, as Page (1987) demonstrated, that students should be willing and able to decode the curriculum discourse of control by themselves before they can concentrate on learning subject matter knowledge. How to decode the system, however, is never taught in any formal instruction because it conflicts with most teachers' belief that educational opportunity is dependent upon students' assuming individual responsibility. It is a belief that the entire teaching profession holds to be true (Anyon, 1997; Carlson, 1992, McQuillan, 1998; Page, 1987) and that Mary held to be true as well: "You come to school, I . . . teach you." Midtown students' behavior changes perceived by Mary and observed in physical education classes demonstrate that the social capital base that the Midtown students have is no longer consistent with what is assumed in the physical education curriculum.

\section{"Now, We are Teaching a Psychology Class, Not PE."}

As a committed physical educator, Mary regularly attends and often presents in workshops in the state AHPERD conventions and has been seeking curricular advice constantly. She has added new units to the curriculum and eliminated from it those no longer favored by the students. The effects of these changes, however, are minimal in terms of addressing the issues that face the students in Midtown High School. Consequently, a sport-centered curriculum with an emphasis on skill development has become an entertainment-oriented program, with a sole objective to maintain order in an educational institution (Ennis, 1995; Page, 1987).

What we have to do is to swing from drills over into actual playing activity, disregard actual skill needs, in many of the respects. So we actually changed the goals of our curriculum to entertain them. That is a major change in the physical education program. Consequently, the skill-learning curriculum has become a playing, entertaining program.

Skill and fitness development are no longer the major goals in daily physical education. During my observation, I recorded many occasions where the teachers, including Mary, prepared their lessons with a focus on skill and fitness development but eventually gave up the planned lessons and turned to their entertaining "back-ups" because of students' resistance. When asked to compare her current goals with those defined in the curriculum guide, Mary responded,

I have to tell you, those goals [in the curriculum guides] are lost in the wayside. What else can I say? . . . Now my primary goal is to get them in our 
classroom, either in the gym or in the activity area. My secondary goal is to have them know my ground rules, basic classroom rules.

Because concern for safety is the first priority in Midtown, teaching the content is no longer considered as important as keeping the classroom in order. Mary described teaching that became "corralling young calves all over a huge field.... I can't let them run loose on campus." The curriculum discourse of control has become the center of daily instruction.

The first thing that comes to my mind is to control the class. I guess it means discipline. Setting my ground rules, so they know what I expect of them. I am not talking about content, teaching skills, or learning skills. I am just saying what they can do and cannot do in my class. I am not teaching. I am trying to get control in my class. I am spending time on discipline, spending time on motivating them to get to class, to be in class, to dress out, to participate. I am not teaching what I was trained to teach. ... I am not spending a lot of time on technique and skill, because now we are teaching a psychology class, not PE.

To achieve the goal of control, Mary used an incentive system to reward the students who dressed properly for and (or) participated in class activities. She also adopted a grading system that was solely based on attendance rather than on knowledge and skill acquisition. Mary admitted,

All the teachers and I haven't given any written or skill tests for almost 5 years because if we do, they don't come to school on that [testing] day. And their parents, or whoever they live with, will protest if their children didn't pass the tests. A lot of them can't pass these tests anyway. So why do I get myself into that kind of trouble?

The termination of the intramural programs took away from students, not only the opportunity but also their interests in playing sports and exercising. The need to keep students in place and in order forced Mary to alter the content involuntarily to satisfy students' interests in entertainment activities.

We had to swing from knowledge and skill over into entertainment. After they have earned their basic points [by dressing out, etc.], they can play anything in class: sports or cards or electronic games, you name it; as long as they stay with us during the class. . . . They learn nothing with regard to skills-nothing, zip, zero.

The unwanted curriculum change has taken a toll on Mary's professional pride and accountability. Although she tries to follow her unit and lesson plans and carefully prepares her instruction and class management, Mary feels that she is not teaching. She experiences a constant sense of powerlessness and an inability to impart any knowledge and skill to students in a way she was trained.

I was not trained to teach this type of classes. ... I am frustrated and ashamed every time I have to compromise with their needs of not participating. . . . It's frustrating to teach now. ... I am not teaching; I am baby sitting my class.

The traditional physical education curriculum in Midtown High School is failing despite the teachers' persistence in implementing it. Acquisition of knowledge 
and skill is no longer the center of teaching. The sport-centered content has been replaced with entertaining activities not described in the formal curriculum documents. Learning achievement is not assessed in terms of knowledge and skill. Gaining control over student behavior has resulted in a loss of control of the content. Although the unfortunate curriculum change can certainly be attributed to many social changes external to the school and physical education, we should not overlook the fact that the traditional physical education curriculum is unable to address the impact of such social changes.

In Midtown High School, the official knowledge in the physical education curriculum includes those sports and activities that are considered representations of European, male, middle-class values in school physical education (Ennis, 1995; Fernández-Balboa, 1993). These sports are taught as part of the ideological property of the dominant culture with a belief that they should be inherited by all. The community and student profiles portrayed by Mary and recorded in my observations indicate that students in such a sociocultural environment are expected to learn within a dilemma created by the inconsistency between the values of the official knowledge and the realities of the negative social changes in the community. Except in physical education classes, few students have access to this ideological property of playing sports on and off campus. It can be assumed that many students do not seek the access due to concerns for personal safety, financial security, or maintenance of social capital among peers.

In such a teaching context, as shown by both Mary's remarks and my observations, teaching the traditional curriculum is an extremely demanding and tiring job for the teachers. Mary and her colleagues (myself included) feel very frustrated at our inability to teach the content. It is apparent that at the center of the conflict is an issue of whether the rights sanctioned in the curriculum, be they property rights or person rights, can be valued by the students and community. At the present time, it seems that Midtown students do not acknowledge the relevance of the ideological property of sports. They have developed a subculture characterized by going through the motions to resist the official knowledge that requires them to inherit an ideological property that they are denied access to in their lives outside of physical education classes.

Similar to many teachers in such a context (Anyon, 1997; Carlson, 1992; McQuillan, 1998), Mary is committed to the subject matter and goals defined in the official curriculum documents but is unable to identify the weakness in the curriculum discourses and school policies that undermines teaching and learning. Understandably and arguably, she was forced to strengthen the curriculum discourse of control and water-down the discourse of knowledge. Without solving the ideological conflict, Mary's persistence in teaching the traditional curriculum has created a learning environment where the prevailing approach is the "pedagogy of poverty" (Waxman, Huang, \& Padron, 1995, p. 13), which emphasizes controlling student behavior rather than teaching appropriate content. In this pedagogical context, social changes, student behavior changes, and the failure of the curriculum form a vicious cycle of nonparticipation, failure, and withdrawal from learning for students.

\section{So What?}

The purpose of this paper was to describe and interpret the impact of social changes on a traditional physical education curriculum in Midtown High School 
that serves a troubled inner-city community. The social changes in the community have had a tremendously negative impact on student behavior in Midtown High School and, consequently, have devastated the physical education curriculum. Mary's descriptions of the changes in the community, in the student population, in the curriculum, and in her daily teaching are consistent with recent research findings on inner-city education and physical education (Anyon, 1997; Carlson, 1992; Ennis, 1995; Ennis et al., 1997; Kantor \& Brenzel, 1992; Martinek, 1996; Martinek \& Griffith, 1994; Waxman et al., 1995). Her recollection of historical events and their influences on the curriculum provides a unique angle that further illustrates how social changes outside of the school and gymnasium can force unwanted changes in the curriculum. The analytical framework of critical pedagogy has helped me in understanding, interpreting, and theorizing about the curriculum change in Midtown. Based on the analysis, I argue that the teachers in Midtown should reform the traditional curriculum by addressing the following two issues.

\section{Student Social Capital}

Coleman suggests (1990) that students' positive social capital is established on many positive relations with people and events involved in their schooling. This social capital should not only support their educational endeavors but also serve as positive inspiration for life. However, under the negative social influences, opportunities for inner-city students to accumulate positive social capital have diminished drastically (Anyon, 1997; McQuillan, 1998). Students in Midtown High School are subject to a social context where positive social capital is scarce both in and outside of the school. In contrast, students, especially those associated with gangs, are much more likely to be exposed to opportunities for obtaining negative social capital when they attempt to gain mobility in such a social environment. For instance, when students think that the curriculum provides little meaning to their lives, they simply resist it. They may even support each other in achieving failure and create a culture to disable their desire and ability for education (McDermott \& Varenne, 1995). At a time when teaching and learning is dominated by the curriculum discourse of control, students may create a culture to make teaching difficult for teachers who are potential sources of positive social capital (McQuillan, 1998).

Critical social capital for successful learning is the students' relationship with the curriculum. This relationship can be represented by the students' positive perceptions of the curriculum and their understanding of the relationship between learning the content and their future lives. An important way for students to accumulate such social capital is to obtain economic resources and opportunities to take part in various school-sanctioned and community-based curricular and extracurricular activities (Stanton-Salazar, 1997). Although most students in Midtown do not appear to be economically disadvantaged (only $27 \%$ received assisted or reduced lunch), their economic independence comes at the expense of possible opportunities to participate in after-school programs. The majority of students $(60 \%)$ work after school, and few students participate in after-school sport or exercise programs. Fewer, according to Mary's perception and my observation in the community, exercise or play sports in the community recreation center. With the elimination of intramural programs, students in Midtown High have rather limited economic recourse and opportunity to accumulate necessary social capital for successful learning in traditional physical education. 
We should take the issue of social capital into account when creating future curricula. Kirk (1990) argued that one major reason for the failure of the traditional curriculum is its "lack of local variation" (p. 412). It is evident in Midtown that the unwanted curriculum changes started in places traditionally beyond the bounds of formal physical education, such as the community recreation center, where playing sports has raised serious concerns for personal safety, or student homes, where outdoor activities are replaced by indoor, sedentary, and entertainment-oriented activities. But those are the very locations in which students can accumulate their social capital for physical education. The curriculum, therefore, should teach students how to make positive advancement in their immediate context, such as helping the community regain control of the recreation center. To do this, teachers should focus on what physical education can do to help students transform their lives in a disadvantageous social environment (Martinek, 1996). From this perspective, teaching golf or basketball should not be determined only on the availability of facilities and equipment, but on an articulation of potential for students to obtain positive social capital for schooling and life. To accomplish this, the issue of dual curriculum discourses (control and knowledge) must be addressed.

\section{Dual Curriculum Discourses}

Sage (1997) analyzed the political, economic, and cultural influences on human movement in terms of its relationships with social class, gender, and race. He pointed out that although various forms of human movement, including athletics, physical education, and institutions (from the International Olympic Organization to a school), represent a wide range of interests associated with human movement-they share a "fundamental function . . . to promote initiatives and activities that help shape the economic, political, and cultural hegemonic structures of the dominant groups" (p. 21). Similar to Apple's (1993) analysis of values in knowledge, Sage concluded that any form of human movement, including the content in physical education, are not neutral or value-free. It is intended to serve the purpose of promoting the dominant, professional middle-class and European American belief that everyone in society can reach the top (measured in monetary and [or] meritocratic terms) as long as individuals take full responsibility "for their own fate" (Sage, 1997, p. 24). Traditional physical education, with hidden and overt curricular intentions, is a contributor to this ideology through reinforcing a meritocratic belief that self-responsibility and hard work lead to superior performance and personal success (Sage, 1997).

This belief further produces a dual-responsibility system which dichotomizes educational responsibility between the two parties involved: teachers and students. Learning is believed to be the responsibility of individual students and maintenance of order in school and classroom is the responsibility of the teacher. While most teachers share and support this belief, few inner-city blue-collar working class families and their children do (Page, 1987). They believe that teachers should be held accountable for student failures if they are unable to make the content learnable for the students. This value differentiation leads to a dilemma in teaching where teachers expect the ideological property, in the form of knowledge and skills in the curriculum, to be inherited by those students whose personal access to such property is denied due to political, socioeconomic, or cultural disadvantages beyond their own control. 
To fulfill their curricular responsibility of control, teachers tend to solve this dilemma by changing what they do in the classroom. The outcome of the change usually is characterized by a watered-down content in exchange for students' compliance in maintaining a controlled, orderly classroom. In an educational environment centered on control of students, teachers are left with few choices other than aligning themselves with the school administration and its emphasis on control. In this situation, teachers become a part of the crisis or the problem more than the solution (Anyon, 1997; Carlson, 1992). As a believer in the dual-responsibility ideology of learning, Mary taught according to this belief. When her students were perceived as not responsible for their own learning, the responsibility to control the classroom guided Mary to turn to the curriculum discourse of control at the expense of the content.

\section{Any Solutions?}

Although negative social changes are blamed from Mary's perspective, I would argue that the inability of the traditional curriculum to address issues associated with the changes has contributed equally to the failure of the curriculum in Midtown. Kirk (1990) pointed out that assuming knowledge and skills to be neutral, generic, and value free decontextualizes our content and prevents teachers from creating a meaningful curriculum. To address curriculum decontextualization in physical education, Kirk (1997) proposed that we should emphasize schoolcommunity connection, in-school and outside-school learning, use of multiple learning sites, individualized instruction, and flexible scheduling compatible with community events. In this context, students can attend classes in their own school as well as in neighboring schools and gain credits through after-school sport and exercise programs under the guidance of physical educators. Physical educators should take the responsibility of professional leadership to integrate collective efforts of school, community, and the health industry for developing a new physical culture.

Such a curriculum reform requires a new theoretical platform based on transformation of knowledge, the person, and community cultures rather than transmission of values, knowledge, and skills (Doll, 1993). As Banks (1993) pointed out, students come to school with the personal-cultural knowledge they have gained at home. They also are influenced by popular knowledge that includes the conception and misconception of natural and social phenomena institutionalized by mass media. In school, students are expected to learn the mainstream academic knowledge in the formal curriculum. At times, however, it is likely that they also are exposed to transformative academic knowledge consisting of the facts, concepts, and theories that challenge the mainstream academic knowledge. Banks (1993) suggested that we need to acknowledge the legitimacy of each knowledge and provide opportunities for students to learn from multiple knowledge perspectives. During learning, personal-cultural and popular knowledge are evaluated within the framework of mainstream and transformative academic knowledge. The academic knowledge, in turn, can be incorporated and internalized into personal-cultural knowledge (Banks, 1993). For example, a student can learn basketball underhand shot, chest shot, onehand stationary shot, and jump shot from a perspective of mainstream academic knowledge that addresses performance proficiency. Or he or she can examine these skills from a social-historical perspective to learn the evolution of shooting skills associ- 
ated with socio-historical changes of the game. Or he or she can analyze them from a critical feminist perspective for an understanding of the relationship between skills and gender.

Learning is incomplete if it occurs without a purpose of transforming the person. This transformation takes place at both belief and behavior levels so that the values and necessity of participation can be internalized when students' personalcultural knowledge intersects with mainstream and transformative knowledge. Transforming belief and behavior relies on the knowledge that students acquire. For example, mass media often manipulate images of exercise, physical activity, and sports for the benefits of the industry (Daddario, 1997; Davis, 1993). Popular knowledge acquired from the media often generates either stereotypical or hyper-realistic beliefs about physical activity and ability. Harrison (1998) reported that African-American male students can easily believe that they have higher ability in basketball than in tennis because of the way the two sports are portrayed in the media and community. Oliver (1998) revealed that female high school students construct the meaning of their bodies and behavior in terms of "fashion-in" and "fashion-out." A physical education curriculum should guide students to transform their beliefs and behaviors in order for them to internalize the benefits of learning in physical education.

Community culture is a source of personal and popular knowledge. Community culture is a special context for school education. It, however, does not necessarily enhance student learning. At times it hinders learning by devaluing schooling (Anyon, 1997). Transforming community culture should be taken as a critical curriculum goal, because the ultimate purpose of physical education is to promote and maintain a healthful lifestyle for all. Achieving this goal requires teachers and students to go beyond the school gymnasium and fields. Lave and Wenger (1991) argued that meaningful learning is situated learning in which the content and learning process are integrated into, rather than isolated from, the sociocultural dynamics of the society. For secondary school students, meaningfulness in physical activity is not limited to those of basic motor skills and physical fitness (Chen, 1998). The curriculum should provide students with valuable experiences by helping them realize the importance of their participation in transforming their community cultures for high quality, healthful living.

\section{References}

Anyon, J. (1997). Ghetto schooling: A political economy of urban educational reform. New York: Teachers College Press.

Apple, M.W. (1975). The hidden curriculum and the nature of conflict. In W. Pinar (Ed.), Curriculum theorizing: The reconceptualists (pp. 95-119). Berkeley, CA: McCutchan. Apple, M.W. (1990). Ideology and curriculum (2nd ed.). New York: Routledge.

Apple, M.W. (1993). Official knowledge: Democratic education in a conservative age. New York: Routledge.

Bain, L. (1976). Description of the hidden curriculum in secondary physical education. The Research Quarterly, 47, 154-160.

Bain, L. (1990). A critical analysis of the hidden curriculum in physical education. In D. Kirk \& R. Tinning (Eds.), Physical education, curriculum, and culture: Critical issues in the contemporary crisis (pp. 23-42). London: Falmer Press.

Banks, J.A. (1993). The canon debate, knowledge construction and multicultural education. Educational Researcher, 22(5), 4-14. 
Berliner, D.C., \& Biddle, B.J. (1995). The manufactured crisis: Myths, fraud, and the attack on American's public schools. Reading, MA: Addison-Wesley.

Carlson, D. (1992). Teachers and crisis: Urban school reform and teachers' work culture. New York: Routledge.

Carlson, T.B. (1995). We hate gym: Student alienation from physical education. Journal of Teaching in Physical Education, 14, 467-477.

Carnegie Council on Adolescent Development. (1989). Turning points: Preparing American youth for the 21st century. New York: Carnegie Corporation.

Chen, A. (1998). Meaningfulness in physical education: A description of high school students' conceptions. Journal of Teaching in Physical Education, 17, 270-306.

Coleman, J.S. (1990). Equality and achievement in education. Boulder, CO: Westview Press.

Cornbleth, C. (1990). Curriculum in context. Bristol, PA: Falmer.

Cuban, L. (1992). Curriculum stability and change. In P.W. Jackson (Ed.), Handbook of research on curriculum (pp. 216-247). New York: Macmillan.

Daddario, G. (1997). Gendered sports programming: 1992 Summer Olympic coverage and the feminine narrative form. Sociology of Sport Journal, 14, 103-120.

Davis, L.R. (1993). Critical analysis of the popular media and the concept of ideal subject position: Sports Illustrated as case study. Quest, 45, 165-181.

Doll, W.E., Jr. (1993). A post-modern perspective on curriculum. New York: Teachers College Press.

Ennis, C.D. (1995). Teachers' responses to noncompliant students: The realities and consequences of a negotiated curriculum. Teaching and Teacher Education, 11, 445-460.

Ennis, C.D., Cothran, C.J., Davidson, K.S., Loftus, S.J., Owens, L., Swanson, L., \& Hopsicker, P. (1997). Implementing curriculum within a context of fear and disengagement. Journal of Teaching in Physical Education, 17, 52-71.

Erickson, F. (1986). Tasks in times: Objects of study in a natural history of teaching. In K.K. Zumwalt (Ed.). Improving teaching: 1986 ASCD Yearbook. Alexandria, VA: Association for Supervision and Curriculum Development.

Fernández-Balboa, J. (1993). Sociocultural characteristics of the hidden curriculum in physical education. Quest, 45, 230-254.

Fernández-Balboa, J.M. (Ed., 1997). Critical postmodernism in human movement, physical education, and sport. Albany, NY: SUNY Press.

Flaxman, E., \& Passow, A.H. (Eds., 1995). Ninety-fourth yearbook of the National Society for the Study of Education: Part II. Changing populations changing schools. Chicago: University of Chicago Press.

Goetz, J.P., \& LeCompte, M.D. (1984). Ethnography and qualitative design in educational research. San Diego, CA: Academic Press.

Harrison, L., Jr. (1998, April). Perceived physical ability as a function of race. Paper presented at the annual meeting of American Educational Research Association, San Diego, CA.

Jewett, A.E., Bain, L.L., \& Ennis, C.D. (1995). The curriculum process in physical education. Dubuque, IA: Wm. C. Brown.

Kantor, H., \& Brenzel, B. (1992). Urban education and the "truly disadvantaged": The historical roots of the contemporary crisis, 1945-1990. Teachers College Records, 94, 278-314.

Kirk, D. (1990). School knowledge and the curriculum package-as-text. Journal of Curriculum Studies, 22, 409-425.

Kirk, D. (1993). Curriculum work in physical education: Beyond the objectives approach? Journal of Teaching in Physical Education, 12, 244-265. 
Kirk, D. (1997). Schooling bodies in new times: The reform of school physical education in high modernity. In J.M. Fernández-Balboa (Ed.). Critical postmodernism in human movement, physical education, and sport (pp. 39-63). Albany, NY: SUNY Press.

Lave, J., \& Wenger, E. (1991). Situated learning: Legitimate peripheral participation. New York: Cambridge University Press.

Lieberman, A. (1992). Introduction: The changing context of education. In Ann Lieberman (Ed.). Ninety-first yearbook of the National Society for the Study of Education: Part I. The changing contexts of teaching (pp. 1-10). Chicago: University of Chicago Press. Locke, L.F. (1992). Changing secondary school physical education. Quest, 44, 361-372.

Martinek, T.J. (1996). Fostering hope in youth: A model for explaining learned helplessness in physical activity. Quest, 48, 409-421.

Martinek, T.J., \& Griffith, J.B. (1994). Learned helplessness in physical education: A developmental study of causal attributions and task persistence. Journal of Teaching in Physical Education, 13, 108-122.

McDermott, R., \& Verenne, H. (1995). Culture as disability. Anthropology and Education Quarterly, 26, 324-348.

McQuillan, P.J. (1998). Educational opportunity in an urban American high school: A cultural analysis. Albany, NY: SUNY Press.

Oliver, K.L. (1998, April). How adolescent girls interpreted and constructed the meanings of their bodies: Learning to create and desire an image. Paper presented at the annual meeting of American Educational Research Association, San Diego, CA.

O'Sullivan, M., Siedentop, D., \& Tannehill, D. (1994). Breaking out: Codependency of high school physical education. Journal of Teaching in Physical Education, 13, 421-428.

Page, R. (1987). Teachers' perceptions of students: A link between classrooms, school cultures, and the social order. Anthropology and Education Quarterly, 18, 77-99.

Patton, M.Q. (1990). Qualitative evaluation and research methods. Newbury Park, CA: Sage.

Pinar, W.F., Reynolds, W.M., Slattery, P., \& Taubman, P.M. (1996). Understanding curriculum. New York: Peter Lang.

Sage, G.H. (1997). Sociocultural aspects of human movement: The heritage of modernism, the need for a postmodernism. In J.M. Fernández-Balboa (Ed.). Critical postmodernism in human movement, physical education, and sport (pp. 11-26). Albany, NY: SUNY Press.

Siedentop, D., Doutis, P. Tsangaridou, N., Ward, P., \& Rauschenbach, J. (1994). Don't sweat gym! An analysis of curriculum and instruction. Journal of Teaching in Physical Education, 13, 375-394.

Stanley, W.B. (1992). Curriculum for utopia: Social reconstructionism and critical pedagogy in the postmodern era. Albany, NY: SUNY Press.

Stanton-Salazar, R.D. (1997). A social capital framework for understanding the socialization of racial minority children and youths. Harvard Educational Review, 67, 1-40.

Strauss, A.L. (1987). Qualitative analysis for social scientists. New York, NY: Cambridge.

Talbert, J.E., McLaughlin, M.W., \& Rowan, B. (1993). Understanding context effects on secondary school teaching. Teachers College Record, 95, 45-68.

Waxman, H.D., Huang, S.L., \& Padron, Y.N. (1995). Investigating the pedagogy of poverty in inner city middle level schools. Research in Middle Level Education, 18, 1-22. 